\title{
Habitat selection by bluetongue lizards (Tiliqua, Scincidae) in tropical Australia: a study using GPS telemetry
}

\author{
Samantha J Price-Rees, Gregory P Brown and Richard Shine*
}

\begin{abstract}
Background: Emerging global positioning system (GPS) technologies can clarify movement patterns of freeranging animals in far more detail than has been possible with previous methods. We conducted long-term (mean, 65 days; maximum, 221 days) GPS radio-tracking of 41 northern bluetongue lizards (Tiliqua scincoides intermedia) and 8 centralian bluetongue lizards (T. multifasciata) at two study sites in northwestern Australia, close to the border between Western Australia and the Northern Territory.

Results: Individuals of both species spent long periods within small and distinctive habitat patches, interspersed with longer directional relocations from one patch to the next. Our sampling showed that these patches of core activity differed significantly from the surrounding landscape in several respects. The patches provided relatively shaded, cool, and damp conditions, with higher grass and more leaf-litter cover. The location of these patches in the landscape is probably determined by drainage patterns, soil moisture-holding ability, and stochastic recruitment of shade trees.
\end{abstract}

Conclusions: These scattered patches provide a critically important habitat for lizards (and probably, other taxa) within this hot dry landscape. Future conservation and management strategies need to prioritize the retention of such sites, at a spatial scale that allows animals to move between them.

Keywords: Abiotic cues, Habitat selection, Spatial ecology, Reptile thermoregulation, Wet-dry tropics

\section{Background}

In all vertebrate species, organisms must move about for such functions as resource acquisition, mate location, predator avoidance, and thermoregulation [1]. Such movements are driven by complex processes that operate over a range of spatial and temporal scales [1-3]. Understanding the factors that influence movement patterns and habitat selection is central to managing species, particularly taxa that are affected by anthropogenic activities $[4,5]$.

Most landscapes are highly heterogeneous, and incorporate environmental variation in many abiotic and biotic conditions that can directly affect organismal fitness [6]. The tropical savanna of northern Australia represents one such region that has an extensive heterogeneous matrix imposed by both a highly seasonal climate [7]

\footnotetext{
* Correspondence: rick.shine@sydney.edu.au

School of Biological Sciences A08, University of Sydney, Sydney, NSW 2006,
} Australia

\section{Biomed Central

(c) 2013 Price-Rees et al.; licensee BioMed Central Ltd. This is an Open Access article distributed under the terms of the Creative Commons Attribution License (http://creativecommons.org/licenses/by/2.0), which permits unrestricted use, distribution, and reproduction in any medium, provided the original work is properly cited. and anthropogenic influences, such as fire and grazing $[8,9]$. These factors influence soil nutrients and water availability and the distribution of vegetation $[10,11]$. In such a patchy habitat, the location that an individual inhabits can influence its physiology [12,13], the availability of food resources $[14,15]$, its exposure to predation $[16,17]$, and its reproductive opportunities $[18,19]$.

For ectotherms such as reptiles, microhabitats often differ in the ease with which an individual can regulate its body temperature [20-24]. In temperate climates, the greatest challenge for an ectotherm may be to obtain body temperatures high enough to facilitate activity, prompting reptiles to shuttle between sheltered microhabitats and more exposed sun-basking sites to maintain suitable body temperatures $[12,20,25,26]$. In the tropics, where ambient temperatures are high all year round [27], reptiles are able to maintain high, stable temperatures without the need for overt thermoregulation: that is, their selection of habitats is more likely to be driven 
by the need to avoid overheating than to find basking sites $[28,29]$. Thus, tropical reptiles may select thermally distinctive microhabitats not to heat up, but to avoid overheating and water loss [30-32]. In the tropics, this 'heat avoidance' behavior probably predominates most of the year, whereas many temperate reptiles face similar thermal challenges for shorter periods (for example, during hot, dry summers [33]). The large temperate-zone scincid lizard Tiliqua rugosa predominately exhibits a 'heat seeking' thermoregulatory behavior, but switches to a 'heat avoidance' strategy to avoid dangerously high temperatures, and to conserve energy reserves and water during summer months [33].

To compare microhabitats from an organism's perspective, we need to define those patches of microhabitat based on movement patterns of free-ranging organisms [34]. The movement ecology paradigm [3] provides objective techniques with which to differentiate between alternative modes of movement, potentially allowing us to compare areas that induce one movement mode (for example, long-distance, rapid dispersal) from areas that induce other movement paths (for example, sedentary, with frequent return to the original location). The logistical limitations of obtaining continuous, accurate locational data have largely precluded this approach with small vertebrates [35]. Recent developments in global positioning system (GPS) technology provide ways to overcome this obstacle [35-38].

The tropical Kimberley region of northern Australia supports a rich diversity of reptile taxa (39\% of the Australian species total), including two species of bluetongue lizard (northern bluetongue Tiliqua scincoides intermedia and centralian bluetongue T. multifasciata [39]). Both are heavy-bodied, short-limbed omnivorous scincids [40,41]. In this study, we use the movement ecology framework to examine mechanisms that influence the movement paths of free-ranging individuals of these two lizard species in tropical Australia, to clarify how these animals respond to habitat heterogeneity. In other analyses based on the same dataset, we have used a maximum likelihood approach to differentiate objectively between interpatch versus intrapatch movement phases by these lizards, and examined the influence of abiotic factors on dispersal rates [42]. Here, we extend this previous research to examine effects of biotic and abiotic characteristics on the lizards' selection of corearea habitats, to better understand the factors that influence movement phases and habitat selection.

\section{Results}

Over two consecutive wet seasons (mid-November to mid-March), we radio-tracked a total of 49 bluetongue lizards (41 northern bluetongues, T. s. intermedia, and 8 centralian bluetongues, T. multifasciata) at two sites in the wet-dry tropics of northwestern Australia. Over the course of this study, we obtained $>60,000$ locations from the GPS system allowing us to distinguish clearly between core areas of high intensity use and areas that were used only infrequently by our radio-tracked lizards.

\section{Point level}

Overall, we conducted a total of 951 point-level habitat surveys (311 at the Northern Territory (NT) study site and 640 at the Western Australia (WA) study site). We found the lizards inactive (coiled within a refuge) at 180 (60\%) of records at the NT study site, and 549 (88\%) of records at the WA study site. Active lizards were generally found in relatively open habitats.

Lizards at the NT study site were predominately located (90\% of locations) in scattered open forest (SF) with a native grass or spinifex understory (Figure 1a, Figure 2a). Lizards rarely occurred in scrubby areas dominated by Acacia leucophloea, or garden habitats (Figure 2a). The SF macrohabitat contained many flooded box or coolibah $(E u-$ calyptus microtheca) with ghost gums (Corymbia bella), Cooktown ironwood (Erythrophleum chlorostachys) and Kimberley bauhinia (Lysiphyllum cunninghamii) also common. At the WA study site, lizards were predominately located in patches of riparian vegetation (R, 56\%; Figure 1d), gardens (G, 14\%), and built environments $(\mathrm{BE}, 12 \%$; see Figure 2a). The dominant tree species in riparian areas was neem (Azadirachta indica, an exotic tree), with a midstory of Acacia species and an understory dominated by buffel grass (Cenchrus ciliaris, an introduced grass), exotic vine and mixed weeds.

In relation to microhabitat, lizards at both study sites were predominately located within grass $(\mathrm{G})$ and shrubs (S) (NT: $46 \%$ and 22\%, respectively; WA: $53 \%$ and 13\%, respectively; see Figures 1 and 2). At the NT study site, lizards (especially T. multifasciata) were also frequently located within spinifex (SX) (16\%; see Figure 2b). Within the NT study site, shrubs typically occurred in discrete patches dominated by white currant bush (Fleuggea virosa melanthesoides), wild grape (Ampelocissus acetosa), native jasmine (Jasminum aemulum), stinking passionflower (Passiflora foetida), rough-leafed fig (Ficus opposita), and Acacia species. Often, these patches occurred around the base of a tree (Figure 1a). At the WA study site, shrubs primarily comprised Acacia sp. and exotic garden species. The dominant grass selected by lizards at the WA site was buffel grass (Figure 1e), a perennial grass up to $1 \mathrm{~m}$ high with a thick dome-shaped coverage (unlike grasses in the surrounding open areas, which were typically erect with a small basal area).

In relation to ground structure, at both study sites, lizards were found primarily within grass and leaf litter (LL) (NT: $35 \%$ and 27\%, respectively; WA: $47 \%$ and $18 \%$, respectively). At the WA study sites, the lizards 


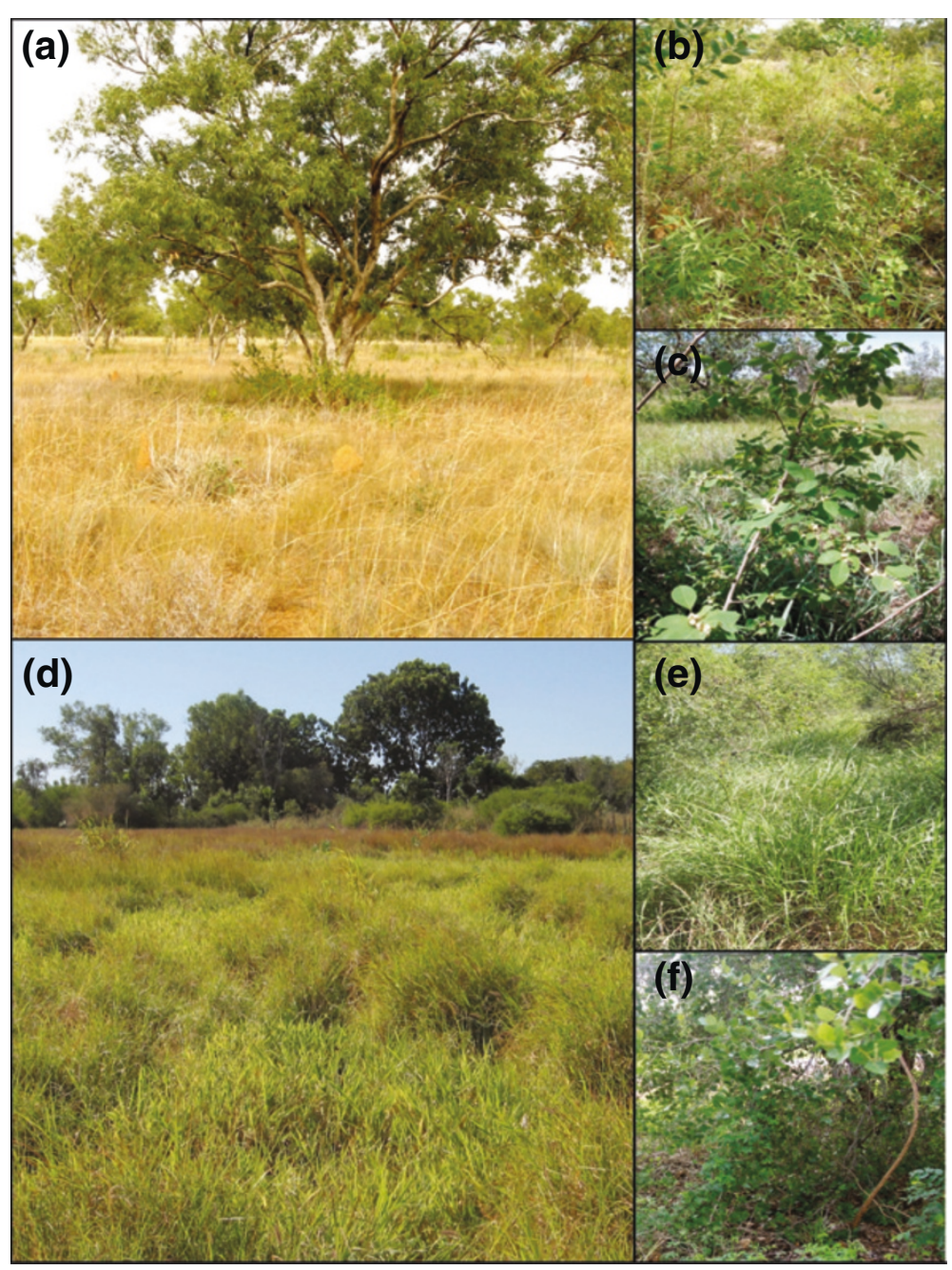

Figure 1 Typical habitats predominantly utilized by bluetongue lizards at two sites within northern Australia. (a,b,c) Keep River National Park, NT and (d,e,f), Kununurra, WA. (a) Scattered open forests dominated by flooded box or coolibah, Eucalyptus microtheca. A typical core area is located at the base of the tree, typical non-preferred areas occur around the periphery. (d) A typical patch of riparian vegetation in the background with non-preferred open paddock habitat in the foreground. Smaller inserts display typical microhabitat characteristics that are associated with core areas: (b) native jasmine, (c) white currant bush, (e) buffel grass, (f) rough-leafed fig.

often used burrows (B) (15\%, probably excavated by varanid lizards), and artificial structures (13\%, built structure (BS) and hard cover (HC) combined). At the NT study site, lizards sometimes used burrows (7\%); spinifex (15\%) was primarily utilized by T. multifasciata (Figure 2c).

Despite considerable differences in overall habitat characteristics of the two study sites, telemetered lizards chose broadly similar microhabitats (based on vegetation characteristics) at both sites (Table 1). Areas where lizards were located had a low proportion of bare ground $(<8 \%)$, a high coverage of grass and leaf litter $(50 \%$ and $>34 \%$, respectively) and usually one or two trees and three or four shrubs within $5 \mathrm{~m}$ of the site selected by the lizard (Table 1; Figure 1).

\section{Effects of vegetation structure}

At the NT study site, principal component analysis (PCA) based on the original eight vegetation structure variables identified four components that explained $83.27 \%$ of variation in habitat parameters (Table 2). The first and second axes from this PCA of vegetation structural data explained $42 \%$ and $18 \%$ of variation, respectively (eigenvalues 3.37 and 1.44). The first axis (PC1) was positively associated with number of trees and shrubs, and leaf-litter depth (Table 2). The second principal component (PC) axis (PC2) also described the number of trees (Table 2). The remaining PC axes described $23 \%$ of the variation, and again represented trees, shrubs and understory cover (PC3), and trees and shrubs (PC4) (Table 2). 


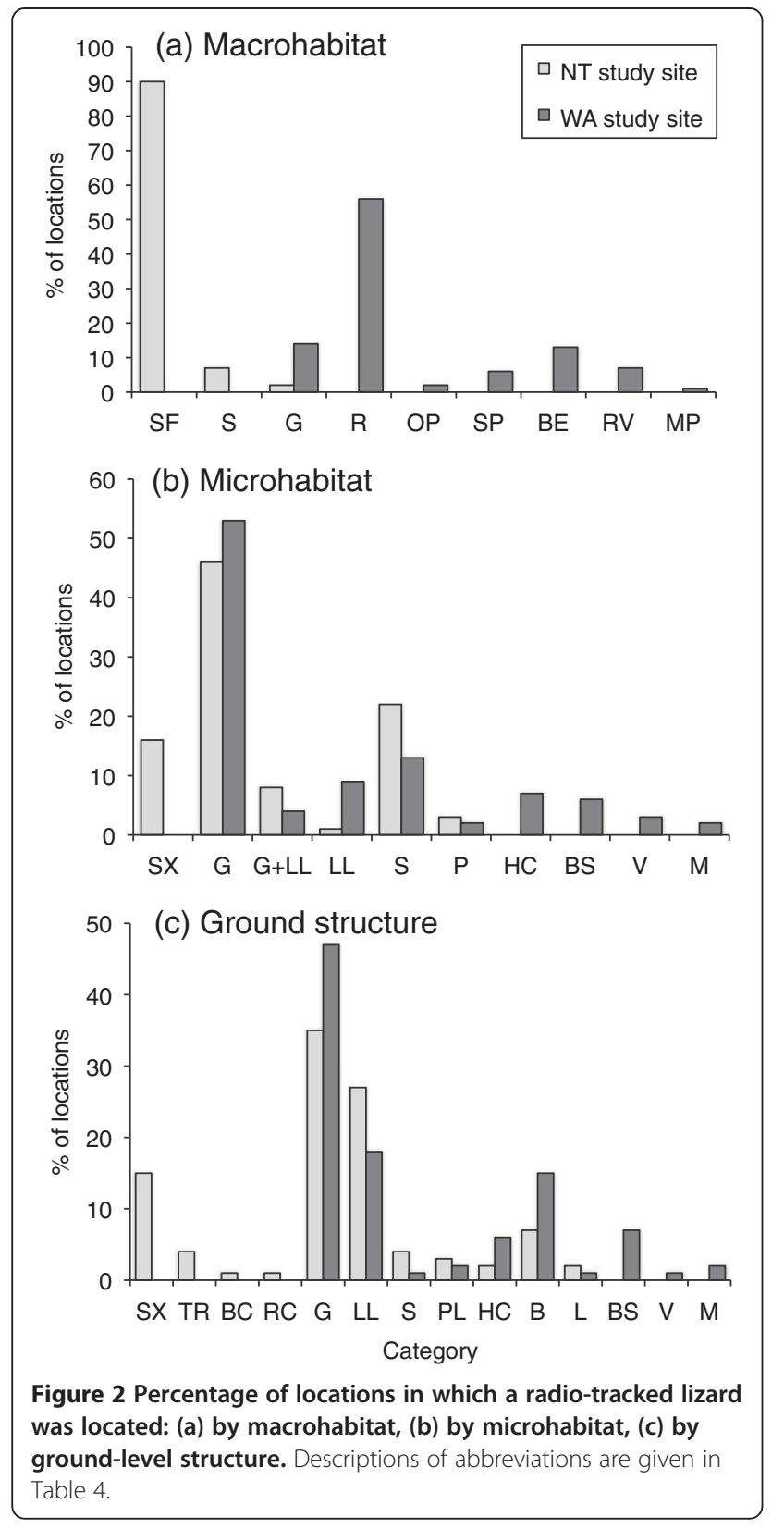

At the WA study site, the PCA also reduced the eight vegetation structural parameters to four PC scores, which together explained $77.37 \%$ of the variation in the dataset (Table 2). The primary axis (PC1) for the PCA explained $34.12 \%$ of the variation and was composed primarily of the number of trees and to a lesser extent the number of shrubs. PC2, which explained $15.74 \%$ of the variation, described the number of trees and shrubs, and amount of bare ground. PC3 (14.83\% of the variation) also had a high loading on number of trees as well as leaf-litter depth. PC4 (12.67\% of the variation) was associated with number of trees (Table 2).

We performed nominal logistic regressions to relate type of habitat (core vs. adjacent, less frequently used) to the four vegetation structure $\mathrm{PC}$ axes derived from our quadrat surveys. Habitat selection by both T. $s$. intermedia, and T. multifasciata at the NT study site was significantly positively related to $\mathrm{PC} 1$ and negatively related to PC2 (Table 3). Thus, lizards spent much of their time within core areas with dense vegetation, especially with more trees and shrubs and thus deeper leaf litter. The same pattern was seen for T. s. intermedia at the WA study site, with core areas containing dense vegetation (trees and shrubs) and minimal exposed ground (PC1 and PC2; see Tables 2 and 3).

\section{Biophysical factors}

At the NT study site, all biophysical parameters that we measured were significantly linked to the PC axes derived from our data on vegetation characteristics. All PC components affected mean temperature (all $P<0.03$ ); PC1 and PC2 affected soil-water-holding capacity and minimum temperature (both have $P<0.02$ ), while PC4 also affected minimum temperature $(P=0.03)$. At the WA study site, PC1 influenced soil-water-holding capacity $(P<0.04)$, maximum temperature $(P<0.03)$, and minimum temperature $(P<0.02)$. Minimum and mean temperatures were also significantly influenced by PC3 ( $P=0.002,0.04$ respectively).

At the NT study site, core areas differed significantly from adjacent, less frequently used parts of the lizards'

Table 1 Habitat variables at sites with located radio-tracked bluetongue lizards in tropical Australia

\begin{tabular}{lcccc}
\hline & \multicolumn{2}{c}{ NT study site } & \multicolumn{2}{c}{ WA study site } \\
\cline { 2 - 5 } Variable & Average & Standard error & Average & Standard error \\
\hline Bare ground (\%) & 7.75 & 0.71 & 3.65 & 0.53 \\
Grass cover (\%) & 49.24 & 2.35 & 34.34 & 1.64 \\
Leaf-litter cover (\%) & 51.00 & 2.45 & 25.25 & 1.71 \\
Understory cover (\%) & 13.46 & 2.01 & 19.93 & 1.40 \\
Canopy cover (\%) & 13.17 & 1.88 & 0.87 & 1.32 \\
Number of trees & 1.49 & 0.09 & 2.95 & 0.06 \\
Number of shrubs & 4.01 & 0.26 & & 0.18 \\
\hline
\end{tabular}


Table 2 Eigenvectors from principal component analysis (PCA) of habitat variables

\begin{tabular}{|c|c|c|c|c|}
\hline PCA axis & PC1 & PC2 & PC3 & PC4 \\
\hline Character & More trees & Heavy canopy & Open & Shaded \\
\hline Eigenvalue & 3.37 & 1.44 & 1.09 & 0.77 \\
\hline$\%$ variation explained & 42.08 & 17.97 & 13.63 & 9.59 \\
\hline \multicolumn{5}{|c|}{ Eigenvectors: NT study site } \\
\hline Bare ground (\%) & -0.006 & 0.01 & 0.0001 & 0.003 \\
\hline Grass cover (\%) & 0.001 & -0.02 & -0.003 & 0.002 \\
\hline Leaf-litter cover (\%) & 0.006 & 0.002 & 0.001 & -0.005 \\
\hline Leaf-litter depth (mm) & 0.03 & 0.01 & 0.005 & -0.03 \\
\hline Understory cover (\%) & 0.007 & 0.002 & 0.04 & -0.01 \\
\hline Canopy cover (\%) & 0.01 & 0.006 & -0.02 & 0.01 \\
\hline Number of trees & 0.12 & -0.10 & -0.26 & -0.12 \\
\hline Number of shrubs & 0.03 & -0.008 & 0.04 & 0.18 \\
\hline Eigenvalue & 2.73 & 1.26 & 1.86 & 1.01 \\
\hline$\%$ variation explained & 34.12 & 15.74 & 14.83 & 12.67 \\
\hline \multicolumn{5}{|c|}{ Eigenvectors: WA study site } \\
\hline Bare ground (\%) & -0.003 & 0.03 & 0.003 & 0.02 \\
\hline Grass cover (\%) & -0.007 & -0.007 & -0.007 & 0.001 \\
\hline Leaf-litter cover (\%) & 0.007 & -0.001 & -0.004 & -0.004 \\
\hline Leaf-litter depth (mm) & -0.001 & -0.002 & 0.04 & -0.008 \\
\hline Understory cover (\%) & 0.005 & 0.01 & -0.006 & -0.02 \\
\hline Canopy cover (\%) & 0.009 & 0.002 & -0.004 & 0.02 \\
\hline Number of trees & 0.20 & -0.22 & 0.08 & 0.21 \\
\hline Number of shrubs & 0.04 & -0.03 & 0.02 & -0.02 \\
\hline
\end{tabular}

Table 3 Nominal logistic regressions showing differences between 'core areas' and less frequently used areas

\begin{tabular}{|c|c|c|c|c|c|c|}
\hline Dependent variable & Source & df & Parameter estimate & $x^{2}$ & $P$ & Model $R^{2}$ \\
\hline \multicolumn{7}{|l|}{ NT study site } \\
\hline \multirow[t]{5}{*}{ T. s. intermedia } & PC1 & 1 & -8.82 & 132.95 & $<0.0001$ & 0.83 \\
\hline & PC2 & 1 & 1.05 & 4.16 & 0.0414 & \\
\hline & PC3 & 1 & -1.59 & 2.90 & 0.0885 & \\
\hline & PC4 & 1 & 1.05 & 1.03 & 0.3090 & \\
\hline & Lizard & 7 & & 27.47 & 0.0003 & \\
\hline \multirow[t]{5}{*}{ T. multifasciata } & PC1 & 1 & -5.67 & 38.32 & $<0.0001$ & 0.72 \\
\hline & PC2 & 1 & 2.73 & 28.91 & $<0.0001$ & \\
\hline & PC3 & 1 & -0.15 & 0.04 & 0.8299 & \\
\hline & PC4 & 1 & -0.49 & 0.22 & 0.6357 & \\
\hline & Lizard & 7 & & 6.33 & 0.3873 & \\
\hline \multicolumn{7}{|l|}{ WA study site } \\
\hline \multirow[t]{5}{*}{ T. s. intermedia } & PC1 & 1 & -2.81 & 11.87 & 0.0006 & 0.92 \\
\hline & PC2 & 1 & 4.26 & 6.92 & 0.0085 & \\
\hline & PC3 & 1 & -0.53 & 0.03 & 0.8640 & \\
\hline & PC4 & 1 & -0.25 & 0.03 & 0.8508 & \\
\hline & Lizard & 6 & & 257.93 & $<0.0001$ & \\
\hline
\end{tabular}


home ranges for all biophysical variables except minimum temperature (soil-water-holding capacity: $F_{1,192}=30.79$, $P<0.0001$; mean temperature: $F_{1,114}=107.29, P<0.0001$; maximum temperature: $F_{1,114}=99.74, P<0.0001$; Figure 3a). There was no significant difference between minimum temperature at used versus unused microhabitats in the NT study site $\left(F_{1,114}=0.72, P=0.398\right)$. On average, minimum temperatures were $24^{\circ} \mathrm{C}$ in both core and adjacent patches. Mean and maximum temperatures were far lower in core patches than in nearby areas $(31 \pm$ $0.5^{\circ} \mathrm{C}$ vs. $34 \pm 0.5^{\circ} \mathrm{C}$ and $43 \pm 1.0^{\circ} \mathrm{C}$ vs. $57 \pm 1.0^{\circ} \mathrm{C}$, respectively). The water-holding capacity of the soil in core areas was greater than in nearby areas where lizards rarely spent time $(60.91 \pm 1.45 \%$ vs. $51 \pm 1.45 \%$; Figure 3a). These biophysical variables also differed between core areas and random sites at the WA study site (soil-water-holding (a) NT study site
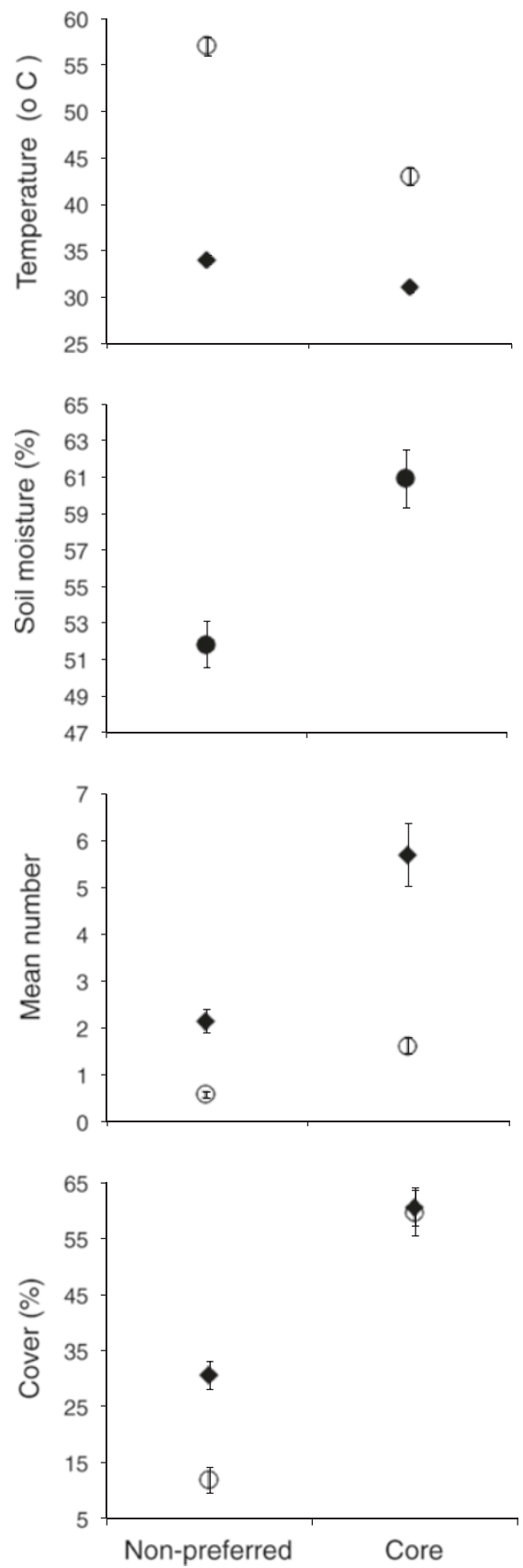

(b) WA study site
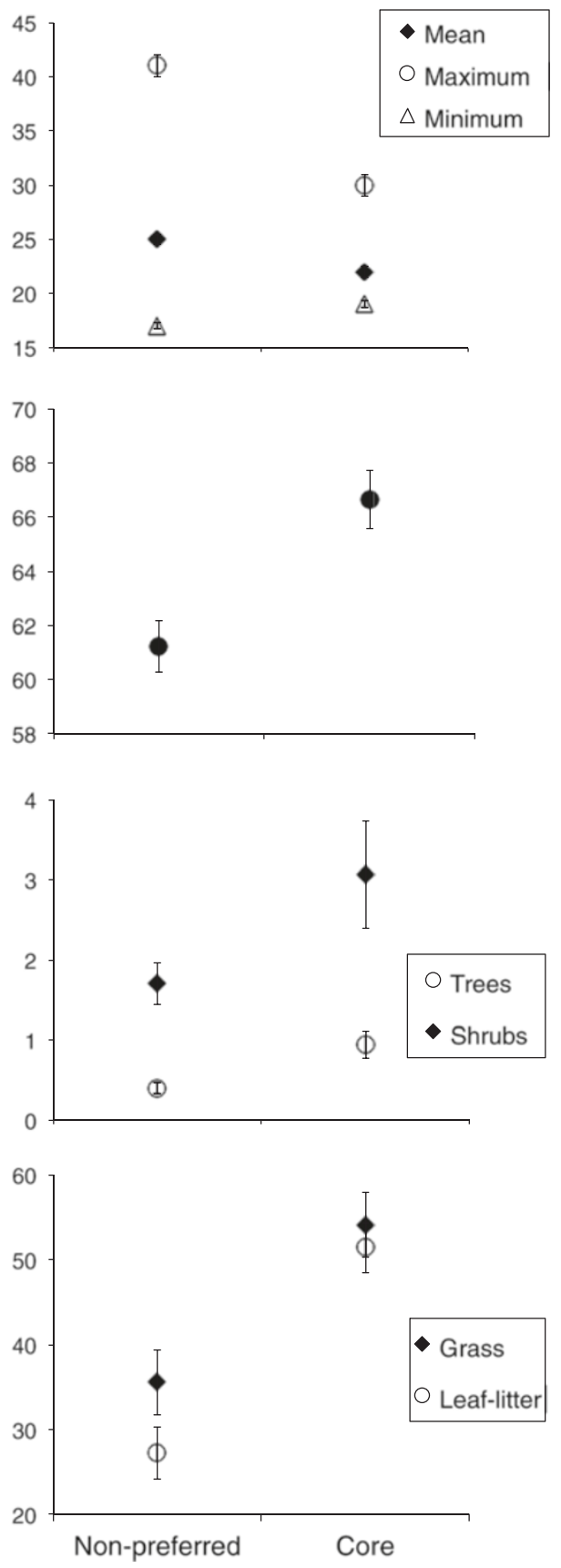

Figure 3 Comparisons between biophysical factors and main vegetation structures of core areas and non-preferred areas used by bluetongue lizards within tropical Australia. (a) NT study site, (b) WA study site. 
capacity: $F_{1,233}=12.91, P=0.0004$; mean temperature: $F_{1,108}=27.80, P<0.0001$; maximum temperature: $F_{1,108}=$ 105.78, $P<0.0001$; minimum temperature: $F_{1,108}=12.82$, $P=0.0005$; Figure $3 \mathrm{~b}$ ). In core patches, mean and maximum temperatures were lower than at nearby random sites $\left(23 \pm 0.5^{\circ} \mathrm{C}\right.$ vs. $25 \pm 0.5^{\circ} \mathrm{C}$ and $30 \pm 1.0^{\circ} \mathrm{C}$ vs. $41 \pm$ $1.0^{\circ} \mathrm{C}$, respectively), whereas minimum temperatures were marginally lower in random sites $\left(17 \pm 0.5^{\circ} \mathrm{C}\right.$ vs. $19 \pm 0.5^{\circ} \mathrm{C}$; Figure $\left.3 \mathrm{~b}\right)$. Minor differences in thermal variables between sites, although statistically significant, are of dubious importance, given that the magnitude of difference is close to the accuracy of the measuring devices. The soil in core areas of lizard home ranges had a greater capacity to retain moisture than did that from adjacent areas that were rarely used by the lizards $(66.66 \pm 0.99 \%$ vs. $61 \pm 1.14 \%$; Figure $3 b)$.

\section{Discussion}

The northwestern tropics of Australia experience variable and challenging climatic conditions. For most of the year the area is hot (daytime maximum air temperatures often $>40^{\circ} \mathrm{C}$ ), with little or no rain during the extended (April to November) dry season. Any diurnally active ectotherm thus faces a high risk of lethal overheating if it remains in sun-exposed habitats; and may also be under hydric stress during prolonged dry periods [30,43-45]. Presumably reflecting those challenges, a high proportion of large reptiles and amphibians living in this region are nocturnally rather than diurnally active $[29,46,47]$. Although bluetongue lizards are active by day $[42,48,49]$, our radiotracking studies have shown that the lizards escape lethally high temperatures in exposed sites by spending much of their time inactive within shaded retreat sites. Those sites are non-randomly distributed across the landscape, with the lizards spending on average $95 \%$ of their time in small core areas that constitute $<40 \%$ of the home range [32].

Analyses in this paper show that those core areas possess a distinctive suite of attributes; basically, they are oases of cool moist sheltered conditions within the otherwise inhospitable landscape. At both study areas, most of those oases consisted of small concentrations of relatively dense vegetation; often, a few trees with a dense shrub or grass understory beneath them, creating a fairly thick ground cover of leaf litter in which the lizards could readily conceal themselves. At the highly disturbed WA site, some of the oases were created by artificial materials (concrete, wood, and so on) rather than by live trees. Despite this difference, both natural and artificially created core areas enabled the lizards to shelter in similar abiotic conditions (cool, moist, protected).

The causal bases for this heterogeneity in shelter opportunities are clear for the artificial shelters (which were constructed in places that people live or work), but obscure for the natural landscape. Small differences in elevation, and thus drainage patterns, as well as increased organic matter $[50,51]$ may have contributed to differences in soil type (and thus, moisture-holding ability), and these soil differences might have been exacerbated by the more profuse growth of vegetation in these small areas [11]. Stochastic events of tree germination and survival were probably also important; once a tree becomes established, its shade may allow the growth of numerous shrubs, and ultimately produce a small patch of moister, cooler conditions at ground level than can be found anywhere in the surrounding landscape.

It is likely that bluetongue lizards benefit from these conditions in a number of ways. Most obviously, they can avoid otherwise-lethal ground temperatures, and maintain water balance [31]. In addition, they are hidden from such predators as snakes, varanid lizards, raptors, and dingoes [52]. Although we did not quantify food availability, we observed more edible fruit, berries, invertebrates and small vertebrates (such as frogs) in the moist leaf litter than would be available elsewhere in the landscape. The differences in soil-water-holding capacity might also translate into a lower probability of inundation; after heavy rain, we often saw extensive pooling of water in areas between but not within core areas. Moister conditions of vegetation and soil within the patches may also provide refuges from fire, at least during low-intensity burns (for example, the early dry and wet seasons $[53,54])$, particularly given the limited ability of bluetongues for rapid movement.

One of the most striking results of our study is the similarity in the attributes of core areas used by both species of bluetongue lizard, and by lizards at both sites. The two lizard species are broadly similar in overall size and morphology, but differ strongly in their geographic distributions and thus, in the range of abiotic conditions that they encounter over most of their extensive ranges. The northern bluetongue (T. s. intermedia) is restricted to the wet-dry tropics, primarily in open woodland habitat, whereas the centralian bluetongue (T. multifasciata) ranges widely across the arid interior, especially in spinifex grassland. The wet-dry tropics inhabited by northern bluetongues experience higher and more seasonally predictable rainfall than do the desert habitats of centralian bluetongues $[55,56]$. Nonetheless, the broad abiotic challenges experienced by the two species are probably fairly similar: an open landscape that is lethally hot for long periods during daylight hours, with scattered patches of denser vegetation that provide shade, food, moisture, and protection from predators. At the site where the two species were sympatric (Keep River), the centralian bluetongues used spinifex clumps (rather than trees) for shelter more often than did the northern bluetongues (Figure 2b,c). This difference is consistent with the 
habitat types experienced by the two lizard species over the rest of their (allopatric) ranges.

The lizards' frequent use of small isolated habitat patches, and the relative scarcity of such patches within the broader landscape, resulted in considerable overlap between individuals in patch use. For example, a single small ( 5 ha, or $5 \times 10^{4} \mathrm{~m}^{2}$ ) patch of dense riparian habitat at the WA study site was used by at least 33 adult northern bluetongues over the course of our 9-month study at that site [32]. Such cohabitation, whether simultaneous or sequential, may substantially increase rates of parasite transmission among individuals [57-60], especially given that the cool, moist conditions in such sites would enhance survival of ectoparasites such as ticks, as well as the larvae of endoparasitic organisms [61]. These focal sites for reptile activity may also play a significant role in the social systems of the species involved, because many tiliquine species display complex sociality [62-69].

The lizards' disproportionate use of small isolated patches of distinctive habitat also has strong implications for their conservation and management. Most obviously, these scattered patches of dense vegetation are critical for population persistence; destruction of such patches (for example, by feral pigs, or by cattle that use the shaded area as a diurnal refuge from sun exposure) would seriously reduce the carrying capacity of the broader landscape for these lizards. Future work could usefully examine issues of core-area connectedness in greater detail. Previous work has suggested that the visual perceptual range of a congeneric species (T. rugosa) is about $20 \mathrm{~m}$, allowing lizards to execute direct movements towards refuge sites within this distance [70]. Thus, the perceptual range of a species is likely to play an important role in how lizards interact and move within the surrounding environment [71]. If habitat degradation reduces connectedness among core-area patches, such that many are isolated by distances too great for the lizards to detect from the nearest remaining patch, even otherwise-suitable remnant habitat patches may remain unused.

Another conservation implication of the lizards' frequent usage of cool moist core areas is a negative one: the same patches will attract highly toxic cane toads (Rhinella marina), an invasive species currently spreading into this region [72-75]. Both bluetongues and toads are physiologically dependent on habitats that provide buffers against environmental extremes. Bluetongues are dependent on habitats that allow them to maintain the appropriate body temperature [23,76,77]. Similarly, cane toads have no morphological or physiological mechanisms to prevent evaporative water loss [78] and select shelter sites in relation to the protection they provide from desiccation [73-76,79]. Toads at the invasion front are highly mobile, and spend daylight hours inactive in relatively cool moist areas [72]. Hence, toads congregate within refuge sites that are likely to be key foraging areas [74]. Bluetongues rely on relatively slow-moving prey, and are able to ingest very large items [80,81]; thus, if encountered, a toad would be an easy target.

\section{Conclusions}

Cane toads pose a major threat to bluetongue populations, which have crashed in tropical Australia as the toad front has expanded westwards [82]. During this study, high bluetongue mortality was observed subsequent to the establishment of the first generation of these new invaders within both study sites (Price-Rees et al. unpublished data). Bluetongues from tropical Australia are highly sensitive to the toads' distinctive toxins, and are likely to die if they attempt to consume even a single toad [82-84]. Thus, one unfortunate consequence of the lizards' preference for moist cool diurnal retreat sites is an increased probability of encounter with a toxic toad. The kinds of habitat-use bias that we have documented in bluetongue lizards are probably widespread in tropical reptiles: in a landscape that is lethally hot for long periods, the optimal refuge habitat will be an area that is cool and moist. The scientific literature on reptile habitat use is dominated by studies of cool-climate species, where behavioral thermoregulation is facilitated by open, sunexposed patches in a cooler moister habitat matrix [13]. However, most reptiles live in the tropics, where the challenge is typically to avoid overheating, rather than to attain high temperatures $[29,46,85]$. Thus, reliance on scattered patches of denser-than-usual vegetation that provide protection from predation, as well as from abiotic extremes, is probably a widespread feature of the ecology of squamate reptiles in many parts of the world.

\section{Methods}

\section{Study site and species}

Although most species from northwestern Australia are poorly known ecologically [86], this biota is under threat from several anthropogenic processes. Recently, the threats posed by overgrazing, agriculture, forestry, altered fire regimes $[87,88]$ have been exacerbated by the arrival of a highly toxic introduced species, the cane toad Rhinella marina [82]. Toad invasion has decimated bluetongue lizard populations in tropical areas of the NT, and may well have the same effect in WA $[82,83]$.

Our research was conducted at two sites within the Kimberley region of the wet-dry tropics. Ambient temperatures remain high all year round, but there is a pronounced seasonal variation in rainfall $(90 \%$ of the 852 $\mathrm{mm}$ average annual rainfall falls during the four-month wet season, from mid-November to mid-March: Bureau of Meteorology 1968 to 2011 [89]). In the first year of 
our study we worked in Keep River National Park, in the far western NT near the border of WA $\left(15^{\circ} 45^{\prime} \mathrm{S}, 129^{\circ} 6^{\prime} \mathrm{E}\right)$. Between November 2009 and March 2010, we tracked both Tiliqua multifasciata and T. scincoides intermedia. This area is largely unaffected by anthropogenic disturbance; the topography within this study area varied from sandstone plateaus and floodplains, in a matrix that is dominated by open eucalypt savanna woodland with an understory of native grasses [90]. The following year, we worked $6 \mathrm{~km}$ west of the town of Kununurra $\left(15^{\circ} 46^{\prime} \mathrm{S}\right.$, $\left.128^{\circ} 44^{\prime} \mathrm{E}\right), 50 \mathrm{~km}$ west of Keep River National Park. Between September 2010 and April 2011, we tracked the sole bluetongue species that occurs at this site (T. s. intermedia). The habitat was dominated by agricultural use, and included established gardens and built structures, roadside verges, and remnant riparian and swamp fragments.

\section{Capture and GPS-tracking of animals}

At the NT study site, we GPS-tracked nine T. s. intermedia (4 male, 5 female) and eight T. multifasciata (3 male, 5 female) for between two and 121 days each. At the WA study site, we GPS-tracked 32 T. s. intermedia (18 male, 14 female) for between three and 221 days each. Lizards were located by driving slowly along roads, and captured by hand. They were fitted with GPS transmitters using a vest-style backpack, and marked with a Trovan Unique $^{\mathrm{Tm}}$ ID-100B implantable transponder chip (Microchips Australia Pty Ltd., Keysborough, Victoria), and their sex determined by hemipene eversion. We also recorded morphology (mass, head width, snout to vent length, and length of hind leg, front leg, tail, and head). For details of capture methodology and transmitter attachment, see [32,37].

Each lizard was fitted with a Sirtrack $\mu$ GPS data logger with a custom-made attachment plate (mass, 24 g; only fitted to lizards $>300$ g; Sirtrack Ltd., Havelock North, New Zealand) and a single-stage VHF transmitter (battery life at $30 \mathrm{ppm}, \sim 10$ months; mass $=7 \mathrm{~g}$ ) so that animals could be relocated and the GPS units retrieved if they became detached. Each GPS unit was programmed with four duty cycles that logged the location of individual lizards every 15 min during two periods of high activity (0600 to $1300 \mathrm{~h} ; 1700$ to $2300 \mathrm{~h}$ ) and every hour during two periods of low activity (2300 to $0600 \mathrm{~h} ; 1300$ to $1700 \mathrm{~h}$ ). Because of the high frequency of fixes (up to 63 per day), we re-caught lizards every 7 to 10 days and recharged the device (while it was still attached to the lizard) for up to two hours, after which lizards were released at their point of capture. At this time, GPS loggers were downloaded and the condition of the backpacks assessed; the backpack was replaced or repaired if necessary. Following release, lizards were visually relocated every 1 to 5 days using VHF telemetry. At each re-location, we recorded the lizard's location, activity, date, time of day, and habitat.

Manufacturer specifications for Sirtrack GPS units claim an accuracy of $<5 \mathrm{~m} 50 \%$ of the time, and $<8 \mathrm{~m}$ $90 \%$ of the time. However, such factors as sedentary behavior, heavy canopy cover and complex terrain can decrease accuracy [91]. Thus, the horizontal dilution of precision (HDOP) recorded for every stored location fix was used to maintain the accuracy of the dataset. The HDOP is a standard measure of GPS accuracy, based on the number of satellites used for each fix and their relative position in the sky (Sirtrack GPS Receivers Manual, Sirtrack, Havelock North, NZ). Lower values indicate the likelihood of more accurate locations (HDOP values $<2=$ most accurate locations; HDOP values $>10=$ low accuracy). We discarded all locations with HDOP $\geq 5$ from our analyses. In addition, regular visual relocations of lizards verified that locations where the lizards were recaptured were the same as those identified by the GPS units.

\section{Surveys of habitat features in 'core areas'}

At the NT study site, we surveyed 106 'core areas' based on the analyses of lizard movements (with one 'random' area surveyed for each core area, so $N=212$ surveys). Of these sites, we also recorded temperatures at hourly intervals over a 24-h period in 61 core-area quadrats and 54 adjacent quadrats in areas less frequently used by lizards; soil samples were collected from all sites (106 core, 106 random). At the WA study site, 249 (141 core; 108 random) core-level habitat surveys were conducted. Temperatures were also recorded at hourly intervals over $24 \mathrm{~h}$ in 59 core-area quadrats and 50 random quadrats; overall, 236 (136 core; 100 random) soil samples were taken. Differing sample sizes reflect the impossibility of taking soil samples from some built environments, and malfunction or loss of iButtons. Overall, between 2,669 and 2,865 temperature measurements were recorded from core and random quadrats at each of the study sites.

\section{Habitat features}

We sampled attributes of the vegetation as well as biophysical variables (soil-water-holding capacity and air temperature). At both study sites, we collected two types of data on habitat parameters. First, we took habitat data whenever we located an animal (at the physical location of the lizard itself) and recorded whether or not the animal was active.

Our second type of analysis was based on a comparison between core areas used by lizards (as defined by GPS data on lizard movements) relative to the surrounding landscape. We did this by setting out a $1 \mathrm{~m} \times 1 \mathrm{~m}$ quadrat within each identified core area, and a paired 
quadrat of the same size located $20 \mathrm{~m}$ from each corearea quadrat, in a random direction. To delineate core areas within each radio-tracked lizard's home range, we used Ranges 8 v2.7 [92,93] to conduct a hierarchical incremental cluster analysis using nearest-neighbor distances. This analysis defines multinuclear core areas by generating a series of isopleths of diminishing percentage use (that is, 99\%, 95\%, 90\%, 85\%, ..., 20\%) and plotting polygons around the clusters (ICPs: incremental cluster polygons [92,93]). This method links clusters of locations and excludes outlying locations by minimizing sums of nearest-neighbor distances as locations with longer distances are added, to define the core areas objectively [92,93]. We used clusters that included $90 \%$ of locations to define the core-use areas (see Figure 4). For each lizard, up to ten of the highest density cores were selected for follow-up surveys; if a lizard had fewer than ten high-density patches, we surveyed all of the core areas that it had used. To locate survey sites, we used the easting and northing of a point within the center of the core cluster, and used the 'go to' function in a handheld GPS (model eTrex ${ }^{\oplus}$; Garmin, Olathe, Kansas, USA) to locate sites for our $1 \mathrm{~m} \times 1 \mathrm{~m}$ quadrat habitat surveys.

To determine random locations for paired quadrat surveys, we paced $20 \mathrm{~m}$ in a randomly allocated direction (obtained by numbering eight compass directions, and randomly drawing a number). If a random location coincided with a core area of the same or neighboring lizards, we discarded the site and randomly selected a different value for the direction. All sites for an individual lizard were surveyed on the same day, and all surveys were completed within a two-week period. At some locations within the WA study site, extensive overlap between conspecifics resulted in large blocks of frequently used areas [32]. Consequently, random sites could not be allocated without coinciding with other core areas. To overcome this problem, random sites were distributed outwards from the periphery of such dense-usage areas.

The spatial scale of this sampling (20 m from each lizard location to the paired 'random' site) was selected for three reasons. First, a site $20 \mathrm{~m}$ away is close enough for a lizard to detect using visual cues; the animals may be unable to detect sites further than this [70]. Second, most daily displacements by radio-tracked lizards were short $(<20 \mathrm{~m}$ : see [42]), suggesting that animals are unlikely to move to an apparently suitable site if it is $>20$ $\mathrm{m}$ away from a lizard's current location. Third, the broader landscape in which the study was conducted was homogeneous open savanna woodland, within which were located the small and distinctive patches of thicker forest in which lizards were usually found. The great spatial extent of the broader savanna habitat meant that samples at any spatial scale from 20 to at least $100 \mathrm{~m}$ would almost inevitably fall within that homogeneous matrix habitat - and thus, the choice of specific sampling distance $(20$ $\mathrm{m})$ would have negligible influence on our results.

In each quadrat, we recorded the number of trees and shrubs within $5 \mathrm{~m}$ of the quadrat center, the percentage

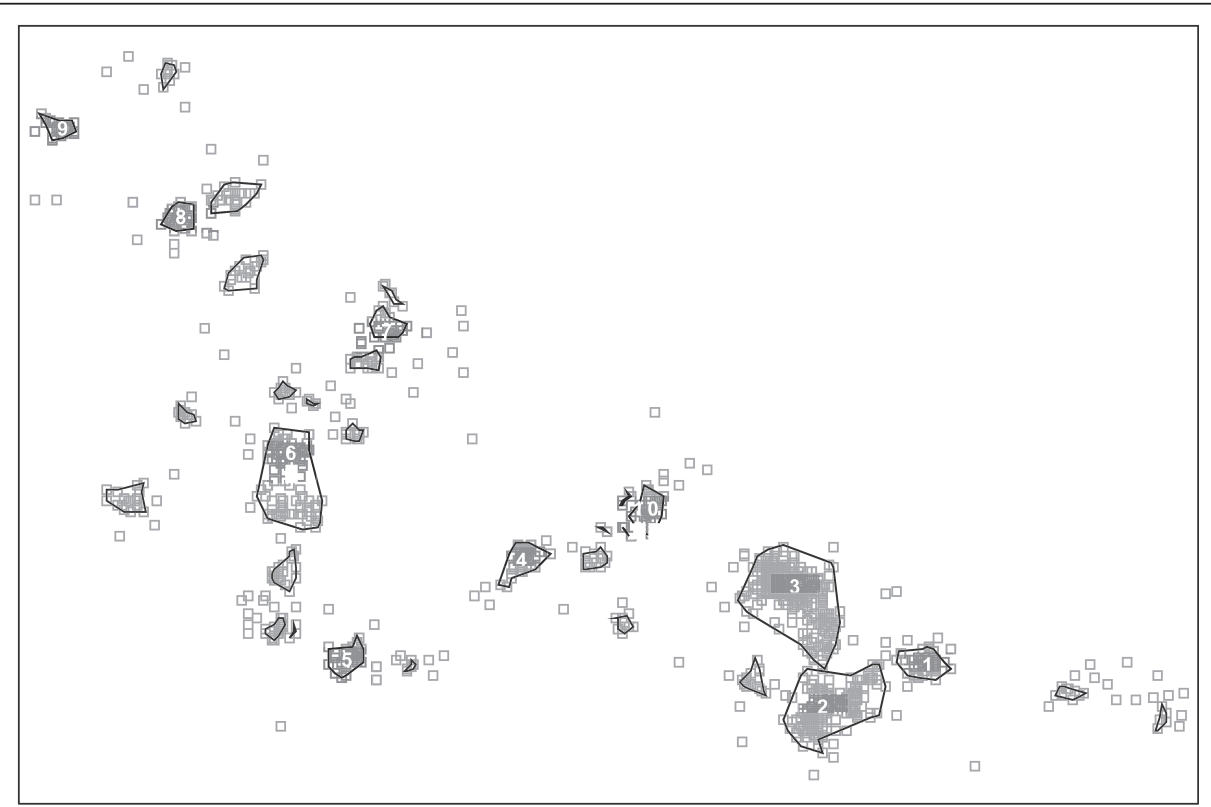

Figure 4 Internal structure of the home range of an individual bluetongue lizard (T. s. intermedia) that was GPS-tracked for 64 days at the NT study site. Hierarchical incremental cluster analysis was used to identify core-use areas within the broader home range, with core areas defined by ICP $90 \%$ isopleths. Numbers show the intensely used core areas that were selected for our habitat surveys. 
cover of canopy, understory, and leaf litter, and the percentage of bare ground and grass. We used categorical variables to describe broad macrohabitat types, understory microhabitat types, and the understory structure (see Table 4). Our classification systems at the two study sites differed slightly because of differences in habitat type (for example, the NT site was drier, and contained spinifex grassland not present at the WA site). At the center of each quadrat, we took a soil sample to determine soil-water-holding capacity (see below), and placed a Thermochron iButton ${ }^{\circ}$ (model DS1921G-F5; Maxim Integrated Products, Sunnyvale, California, USA; accuracy: $\pm 1^{\circ} \mathrm{C}$, temperature resolution: $0.5^{\circ} \mathrm{C}$, operating temperature range: $-40^{\circ} \mathrm{C}$ to $+85^{\circ} \mathrm{C}$ ) in every second quadrat (core and paired random site) to obtain 24-h temperature data. The iButtons were programmed to read temperature at 60 -min intervals over the 24-hr period. If a lizard had five or fewer core areas, an iButton was placed in every quadrat. To quantify temperatures that lizards would experience, iButtons were placed in a location within each quadrat that best represented a potential refuge site. These placements were based on visual observation of the locations of telemetered lizards. The iButtons were placed on the

Table 4 Categories of broad macrohabitat types, understory microhabitat types, and ground-level structures recorded during point-level surveys

\begin{tabular}{|c|c|c|c|c|}
\hline Habitat variable & Location & Classification & Abbreviation & Description \\
\hline \multirow[t]{9}{*}{ Macrohabitat } & NT & Scattered open forest & SF & Scattered tall, limited understory (grass/spinifex) \\
\hline & NT & Scrub & S & Thick patches of shrubs \\
\hline & NT, WA & Garden & G & Artificial to semi-natural human vegetated area \\
\hline & WA & Riparian & $\mathrm{R}$ & Vegetated patches of native and non-native species \\
\hline & WA & Open paddock & $\mathrm{OP}$ & Paddock with no vegetation, grass or bare only \\
\hline & WA & Scrub paddock & SP & Thick patches of shrubs, within an OP \\
\hline & WA & Built environment & $\mathrm{BE}$ & Human-built structures, such as sheds, houses \\
\hline & WA & Roadside verge & RV & \\
\hline & WA & Mango plantation & MP & \\
\hline \multirow[t]{9}{*}{ Understory microhabitat } & NT & Spinifex & SX & \\
\hline & NT, WA & Grass & G & \\
\hline & NT, WA & Leaf litter & $\mathrm{LL}$ & \\
\hline & NT, WA & Shrubs & S & \\
\hline & NT, WA & Pandanus & $P$ & \\
\hline & NT, WA & Hard cover & $\mathrm{HC}$ & Piles of metal or wood, tin, pipes and drains, and such like \\
\hline & WA & Built structure & BS & Demountable, cupboard, fridge, and such like \\
\hline & WA & Vines & V & \\
\hline & WA & Mulch & M & \\
\hline \multirow[t]{14}{*}{ Ground structure } & NT & Spinifex & SX & \\
\hline & NT & Tree roots & TR & From fallen or eroded trees \\
\hline & NT & Black-soil cracks & BC & \\
\hline & NT & Rock crevice & $\mathrm{RC}$ & \\
\hline & NT, WA & Grass & G & \\
\hline & NT, WA & Leaf litter & $\mathrm{LL}$ & \\
\hline & NT, WA & Shrubs & S & \\
\hline & NT, WA & Pandanus leaves & $\mathrm{PL}$ & \\
\hline & NT, WA & Hard cover & $\mathrm{HC}$ & Piles of metal/wood, tin, pipes and drains, and such like \\
\hline & NT, WA & Burrow & B & \\
\hline & NT, WA & Log & L & \\
\hline & WA & Built structure & BS & Demountable, cupboard, fridge, and such like \\
\hline & WA & Vines & V & \\
\hline & WA & Mulch & M & \\
\hline
\end{tabular}


ground within structures (for example, leaf litter, grass clumps). If ground-level structures were absent from the quadrat, iButtons were placed on the bare ground. For each lizard, we calculated mean, minimum, and maximum temperature for every quadrat sampled.

To assess the influence of soil characteristics, we quantified the water-holding capacity of soils from core areas and nearby 'random' areas using methodology modified from Warner et al. [19]. Both rainfall regime and soil types play a critical role in shaping tropical savanna ecosystems. The soil's capacity to hold water can determine the composition of specific plant communities that can grow and persist throughout the dry season [7]. For example, during the wet season, soil is inundated with a surplus of water from monsoon rains but in the dry season porous soils with high clay content quickly lose this moisture, whereas loamier soils retain more water [7]. Thus, we measured the capacity of each soil sample to retain water, rather than the amount of moisture contained in a soil sample at the time of its collection. Soil samples from the center of each quadrat were placed in sealed plastic bags, and weighed prior to drying. To ensure that no moisture remained before testing, all samples were then dried, by placing the opened bags in a closed air-conditioned room maintained at $18^{\circ} \mathrm{C}$ for at least two weeks (until consecutive weighings revealed no further decrease in mass). Three subsamples of approximately $10 \mathrm{ml}$ volume (uncompacted) were removed from each sample and placed into pieces of circular filter paper $(90 \mathrm{~mm}$ diameter; Whatman International, Catalogue No. 1002090) stapled into a cone shape. The soil within the filter paper was weighed to the nearest $0.01 \mathrm{~g}$, and then held upright in a rack of plastic vials. Once samples were arranged on the rack, $10 \mathrm{ml}$ of tap water was added to the surface of each sample using a syringe. A pilot study determined that this volume exceeded the maximum capacity of any soil to retain (that is, no soil sample of $10 \mathrm{ml}$ volume could retain $10 \mathrm{ml}$ of water). Samples were reweighed after $45 \mathrm{~min}$. The percentage water-holding capacity of the soil samples was calculated using the equation:

$$
u=\frac{m_{w e t}-m_{d r y}}{m_{d r y}} * 100
$$

Where $m_{\text {wet }}$ is the saturated mass of the soil sample and $m_{\mathrm{dry}}$ is the initial dry mass of the soil sample before wetting.

\section{Data analysis}

Differences between habitat parameters as recorded at the point level (that is, individual locations of radiotracked lizards) versus the core level (that is, habitat surveys) were evaluated with Pearson's chi-square $\left(\chi^{2}\right)$ test using JMP version 8.0 (SAS Institute, Cary, North Carolina, USA).

We conducted PCA on the habitat parameters (using JMP 8.0) to reduce the number of separate variables included in our analyses. Because the landscape types differed between the two study sites, we subjected vegetation structure variables from each site to separate PCAs. A nominal logistic regression analysis was used to identify effects of the most important PCs on lizard habitat selection (core areas vs. adjacent sites).

We used multivariate regression to assess the association between biophysical variables and the PCs.

To test whether biophysical variables differed between the core areas used by lizards versus less frequently used adjacent sites, we performed an analysis of variance with area type (core area vs. adjacent) as the factor and soilwater-holding capacity, and mean, minimum, and maximum temperature as dependent variables.

\section{Abbreviations}

GPS: Global positioning system; HDOP: Horizontal dilution of precision; ICP: Incremental cluster polygon; NT: Northern Territory; PC: Principal component; PCA: Principal component analysis; SF: Scattered open forest; WA: Western Australia.

\section{Competing interests}

The authors declare that they have no competing interests.

\section{Authors' contributions}

SJPR, GPB, RS conceived and designed research; SJPR performed research; SJPR, GPB, RS analyzed data; and SJPR, RS wrote the manuscript. All authors read and approved the final manuscript.

\section{Acknowledgements}

We thank the rangers at Keep River National Park, NT (especially Cameron Sharpe) for their logistical assistance, the WA Department of Environment and Conservation, Kununurra (in particular, Dave Grosse and Corrin Everitt) for their enthusiasm and logistical support, Bill Stewart for assistance with collection of animals, and Carina Meyer, Lee Howard, Lisa Ward, Barbara Price-Rees, Jai Thomas, Mitch Scott, and Elysia Harradine for assistance with fieldwork. Our work was funded by the Australian Research Council and conducted under permits from the University of Sydney Animal Care and Ethics Committee, the Parks and Wildlife Commission of the NT, and the Western Australian Department of Environment and Conservation.

Received: 24 July 2012 Accepted: 18 April 2013

Published: 7 June 2013

\section{References}

1. Swingland IR, Greenwood PJ: The Ecology of Animal Movement. Oxford: Clarendon; 1983.

2. Johnson $C T$, Parker KL, Heard DC, Gillingham MP: Movement parameters of ungulates and scale-specific responses to the environment. J Anim Ecol 2002, 71:225-235.

3. Nathan R, Getz WM, Revilla E, Holyoak M, Kadmon R, Saltz D, Smouse PE: A movement ecology paradigm for unifying organismal movement research. Proc Natl Acad Sci USA 2008, 105:19052-19059.

4. Bolger DT, Newmark WD, Morrison TA, Doak DF: The need for integrative approaches to understand and conserve migratory ungulates. Ecol Lett 2008, 11:63-77.

5. Germano JM: Movements, home ranges, and capture effect of the endangered Otago skink (Oligosoma otagense). J Herpetol 2007, 41:179-186 
6. Johnson AR, Wiens JA, Milne BT, Crist TO: Animal movements and population dynamics in heterogeneous landscapes. Landscape Ecol 1992, 7:63-75.

7. Williams RJ, Duff GA, Bowman D, Cook GD: Varying the composition and structure of tropical savannas as a function of rainfall and soil texture along a large-scale climatic gradient in the Northern Territory, Australia. Biogeography 1996, 23:747-756.

8. Bradshaw CJA: Little left to lose: deforestation and forest degradation in Australia since European colonization. J Plant Ecol 2012, 5:109-120.

9. Petty AM, Werner PA, Lehmann CER, Riley JE, Banfai DS, Elliott LP: Savanna responses to feral buffalo in Kakadu National Park, Australia. Ecol Monogr 2007, 77:441-463.

10. Fensham RJ, Fairfax RJ, Butler DW, Bowman D: Effects of fire and drought in a tropical eucalypt savanna colonized by rain forest. Biogeography 2003, 30:1405-1414

11. Walker $B H$, Langridge $J$ : Predicting savanna vegetation structure on the basis of plant available moisture (PAM) and plant available nutrients (PAN): a case study from Australia. J Biogeogr 1997, 24:813-825

12. Bashey F, Dunham AE: Elevational variation in the thermal constraints and microhabitat preference of the greater earless lizard Cophosaurus texanus. Copeia 1997, 1997:725-737.

13. Huey RB: Physiological consequences of habitat section. Am Nat 1991, 137:91-115

14. Durtsche RD: Foraging ecology of the fringe-toed lizard, Uma inornata, during periods of high and low food abundance. Copeia 1995, 1995:915-926.

15. Hews DK: Food resources affect female distribution and male mating opportunities in the iguanian lizard Uta palmeri. Anim Behav 1993 46:279-291.

16. Bos DG, Carthew SM, Lorimer MF: Habitat selection by the small dasyurid Ningaui yvonneae (Marsupialia: Dasyuridae) in South Australia. Austral Ecol 2002, 27:103-109.

17. Schauber EM, Connors MJ, Goodwin BJ, Jones CG, Ostfeld RS: Quantifying a dynamic risk landscape: heterogeneous predator activity and implications for prey persistence. Ecology 2008, 90:240-251.

18. Danchin E, Boulinier T, Massot M: Conspecific reproductive success and breeding habitat selection: implications for the study of coloniality. Ecology 1998, 79:2415-2428.

19. Warner DA, Jorgensen CF, Janzen FJ: Maternal and abiotic effects on egg mortality and hatchling size of turtles: temporal variation in selection over seven years. Funct Ecol 2010, 24:857-866.

20. Bauwens D, Castilla AM, Mouton PLN: Field body temperatures, activity levels and opportunities for thermoregulation in an extreme microhabitat specialist, the girdled lizard (Cordylus macropholis). J Zool 1999, 249:11-18.

21. Avery RA: The role of thermoregulation in lizard biology: predatory efficiency in a temperate diurnal basker. Behav Ecol Sociobiol 1982, 11:261-267.

22. Burrow AL, Kazmaier RT, Hellgren EC, Ruthven DC: Microhabitat selection by Texas horned lizards in Southern Texas. J Wildl Manage 2001 65:645-652.

23. Kerr GD, Bull CM: Microhabitat use by the scincid lizard Tiliqua rugosa: exploiting natural temperature gradients beneath plant canopies J Herpetol 2004, 38:536-545.

24. Kerr GD, Bull CM, Burzacott D: Refuge sites used by the scincid lizard Tiliqua rugosa. Austral Ecol 2003, 28:152-160.

25. Adolph S: Influence of behavioral thermoregulation on microhabitat use by two Sceloporus lizards. Ecology 1990, 71:315-327.

26. Langkilde T, O'Connor D, Shine R: Shelter-site use by five species of montane scincid lizards in south-eastern Australia. Aust J Zool 2003, 51:175-186.

27. Wikelski M, Hau M, Wingfield JC: Seasonality of reproduction in a neotropical rain forest bird. Ecology 2000, 81:2458-2471.

28. Kearney M, Phillips BL, Tracy CR, Christian KA, Betts G, Porter WP: Modelling species distributions without using species distributions: the cane toad in Australia under current and future climates. Ecography 2008, 31:423-434

29. Shine R, Madsen $\mathrm{T}$ : Is thermoregulation unimportant for most reptiles? An example using water pythons (Liasis fuscus) in tropical Australia. Physiol Zool 1996, 69:252-269.
30. Christian KA, Corbett LK, Green B, Weavers BW: Activity and energetics of two species of varanid lizards in tropical Australia. Oecologia 1995, 103:349-357.

31. Christian KA, Webb JK, Schultz TJ: Energetics of bluetongue lizards (Tiliqua scincoides) in a seasonal tropical environment. Oecologia 2003 136:515-523.

32. Price-Rees SJ, Brown GP, Shine R: Spatial ecology of bluetongue lizards (Tiliqua spp.) in the Australian wet-dry tropics. Austral Ecol 2012. doi:10.1111/j.1442-9993.2012.02439.x.

33. Ellis DJ, Firth BT, Belan I: Interseasonal variation in the circadian rhythms of locomotor activity and temperature selection in sleepy lizards, Tiliqua rugosa. J Comp Physiol A 2008, 194:701-712.

34. Kotliar NB, Wiens JA: Multiple scales of patchiness and patch structure: a hierarchical framework for the study of heterogeneity. Oikos 1990, 59:253-260.

35. Wikelski M, Kays RW, Kasdin JN, Thorup K, Smith JA, Swenson JGW: Going wild: what a global small-animal tracking system could do for experimental biologists. J Exp Biol 2007, 210:181-186.

36. Flesch JS, Duncan MG, Pascoe JH, Mulley RC: A simple method of attaching GPS tracking devices to free-ranging lace monitors (Varanus varius). Herpetol Conserv Biol 2009, 4:411-414.

37. Price-Rees SJ, Shine R: A backpack method for attaching GPS transmitters to bluetongue lizards (Tiliqua, Scincidae). Herpetol Conserv Biol 2011, 6:150-156.

38. Roshier DA, Asmus MW: Use of satellite telemetry on small-bodied waterfowl in Australia. Mar Freshw Res 2009, 60:299-305.

39. Woinarski JCZ: Biogeography and conservation of reptiles, mammals and birds across north-western Australia: an inventory and base for planning an ecological reserve system. Wildl Res 1992, 19:665-705.

40. Shea G: The systematics and reproduction of bluetongue lizards of the genus Tiliqua (Squamata: Scincidae). PhD thesis. University of Sydney, Department of Veterinary Anatomy; 1992.

41. Shea G: Australian bluetongues. Nature Aust Summer 1998, 1998-99:31-39.

42. Price-Rees SJ: Ecology and impact of invasive cane toads (Rhinella marina) on bluetongue lizards in Northern Australia. PhD thesis. University of Sydney, School of Biological Sciences; 2011.

43. Christian KA, Griffiths AD: Physiological ecology of frillneck lizards in a seasonal tropical environment. Oecologia 1996, 106:49-56.

44. Cloudsley-Thompson $\mathrm{J}$ : Rhythmic activity, temperature-tolerance, waterrelations and mechanism of heat death in a tropical skink and gecko. J Zool 1965, 146:55-69.

45. Hailey A, Coulson IM: Temperature and the tropical tortoise Kinixys spekii: constraints on activity level and body temperature. J Zool 1996, 240:523-536.

46. Anderson NL, Hetherington TE, Coupe B, Perry G, Williams JB, Lehman J: Thermoregulation in a nocturnal, tropical, arboreal snake. $J$ Herpetol 2005, 39:82-90.

47. Brown GP, Shine R, Madsen T: Spatial ecology of slatey-grey snakes (Stegonotus cucullatus, Colubridae) on a tropical floodplain. J Trop Ecol 2005, 21:605-612.

48. Kerr GD, Bull CM: Movement patterns in the monogamous sleepy lizard (Tiliqua rugosa): effects of gender, drought, time of year and time of day. J Zool 2006, 269:137-147.

49. Koenig J, Shine R, Shea G: The ecology of an Australian reptile icon: how do blue-tongued lizards (Tiliqua scincoides) survive in suburbia? Wildl Res 2001, 28:215-227.

50. Hudson BD: Soil organic matter and available water capacity. J Soil Water Conserv 1994, 49:189-194.

51. Leu J, Traore S, Wang Y, Kan C: The effect of organic matter amendment on soil water holding capacity change for irrigation water saving: case study in Sahelian environment of Africa. Sci Res Essays 2010, 5:3564-3571.

52. Fitzsimons JA: Predation on a blotched bluetongue lizard (Tiliqua nigrolutea) by a highlands copperhead (Austrelaps ramsayi) in the Blue Mountains, Australia. Herpetol Notes 2011, 4:259-260.

53. Braithwaite RW: Effects of fire regimes on lizards in the wet-dry tropics of Australia. J Trop Ecol 1987, 3:265-275.

54. Russell KR, Van Lear DH, Guynn DCJ: Prescribed fire effects on herpetofauna: review and management implications. Wildl Soc Bull 1999, 27:374-384

55. Pianka ER: Habitat specificity, speciation, and species density in Australian desert lizards. Ecology 1969, 50:498-502. 
56. Wilson S, Swan G: A Complete Guide to Reptiles of Australia. 3rd edition. Sydney: New Holland Publishers; 2010.

57. Bull CM: Dispersal of the Australian reptile tick by host movement. Aust J Zool 1978, 26:689-697.

58. Corner LAL, Pfeiffer DU, Morris RS: Social-network analysis of Mycobacterium bovis transmission among captive brushtail possums (Trichosurus vulpecula). Prevent Vet Med 2003, 59:147-167.

59. Leu ST, Kappeler PM, Bull CM: Refuge sharing network predicts ectoparasite load in a lizard. Behav Ecol Sociobiol 2010, 64:1495-1503.

60. Main AR, Bull CM: The impact of tick parasites on the behaviour of the lizard Tiliqua rugosa. Oecologia 2000, 122:574-581.

61. Bull CM, Burzacott D: Temporal and spatial dynamics of a parapatric boundary between two Australian reptile ticks. Mol Ecol 2001, 10:639-648.

62. Bull CM, Doherty M, Schulze LR, Pamula Y: Recognition of offspring by females of the Australian skink, Tiliqua rugosa. J Herpetol 1994, 28:117-120

63. Bull CM, Lindle C: Following trails of partners in the monogamous lizard, Tiliqua rugosa. Acta Ethol 2002, 5:25-28.

64. Chapple DG: Ecology, life-history, and behavior in the Australian scincid genus Egernia, with comments on the evolution of complex sociality in lizards. Herpetol Monogr 2003, 17:145-180.

65. Duffield G, Bull CM: Stable social aggregations in an Australian lizard, Egernia stokesii. Naturwissenschaften 2002, 89:424-427.

66. Graves BM, Halpern M: Discrimination of self from conspecific chemical cues in Tiliqua scincoides (Sauria: Scincidae). J Herpetol 1991, 25:125-126.

67. Main AR, Bull CM: Mother-offspring recognition in two Australian lizards, Tiliqua rugosa and Egernia stokesii. Anim Behav 1996, 52:193-200.

68. O'Connor D, Shine R: Lizards in 'nuclear families': a novel reptilian social system in Egernia saxatilis (Scincidae). Mol Ecol 2003, 12:743-752.

69. Osterwalder K, Klingenböck K, Shine R: Field studies on a social lizard: home range and social organization in an Australian skink, Egernia major. Austral Ecol 2004, 29:241-249.

70. Auburn ZM, Bull CM, Kerr GD: The visual perceptual range of a lizard, Tiliqua rugosa. J Ethol 2009, 27:75-81.

71. Olden JD, Schooley RL, Monroe JB, Poff NL: Context dependent perceptual ranges and their relevance to animal movements in landscapes. J Anim Ecol 2004, 73:1190-1194.

72. Brown GP, Kelehear C, Shine R: Effects of seasonal aridity on the ecology and behaviour of invasive cane toads in the Australian wet-dry tropics. Funct Ecol 2011, 25:1339-1347.

73. Schwarzkopf L, Alford RA: Desiccation and shelter-site use in a tropical amphibian: comparing toads with physical models. Funct Ecol 1996, 10:193-200

74. Seebacher F, Alford RA: Movement and microhabitat use of a terrestrial amphibian (Bufo marinus) on a tropical island: seasonal variation and environmental correlates. J Herpetol 1999, 33:208-214.

75. Seebacher F, Alford RA: Shelter microhabitats determine body temperature and dehydration rates of a terrestrial amphibian (Bufo marinus). J Herpetol 2002, 36:69-75.

76. Smith GR, Ballinger RE: The ecological consequences of habitat and microhabitat use in lizards: a review. Contemp Herpetol 2001, 3:1-37.

77. Kerr GD, Bull CM, Cottrell GR: Use of an 'on board' datalogger to determine lizard activity patterns, body temperature and microhabitat use for extended periods in the field. Wildl Res 2004, 31:171-176.

78. Wygoda ML: Low cutaneous evaporative water loss in arboreal frogs. Physiol Zool 1984, 57:329-337.

79. Cohen MP, Alford RA: Factors affecting diurnal shelter use by the cane toad, Bufo marinus. Herpetologica 1996, 52:172-181.

80. Greer AE: Biology and Evolution of Australian Lizards. Sydney: Surrey Beatty and Sons; 1989.

81. Yeatman EM: Resource partitioning by three congeneric species of skink (Tiliqua) in sympatry in South Australia. PhD thesis. Flinders University, School of Biological Sciences; 1988.

82. Price-Rees SJ, Brown GP, Shine R: Predation on toxic cane toads (Bufo marinus) may imperil bluetongue lizards (Tiliqua scincoides intermedia, Scincidae) in tropical Australia. Wildl Res 2010, 37:166-173.

83. Price-Rees SJ, Brown GP, Shine R: Interacting impacts of invasive plants and invasive toads on native lizards. Am Nat 2012, 179:413-422.

84. Licht LE, Low B: Cardiac response of snakes after ingestion of toad parotoid venom. Copeia 1968 (3):547-551.
85. Kearney MR, Shine R, Porter WP: The potential for behavioral thermoregulation to buffer 'cold-blooded' animals against climate warming. Proc Natl Acad Sci USA 2009, 10:3835-3840.

86. Luiselli L, Akani GC: Is thermoregulation really unimportant for tropical reptiles? Comparative study of four sympatric snake species from Africa. Oecologica 2002, 23:59-68.

87. Bowman DMJS: Aims and achievements in Northern Territory forest wildlife biology. In Conservation of Australia's Forest Fauna. Edited by Lunney D. Sydney: Royal Zoological Society of New South Wales; 1998:205-219.

88. Ceballos G, Ehrlich PR: Mammal population losses and the extinction crisis. Science 2002, 296:904-907.

89. Bureau of Meteorology 1968 to 2011. [www.bom.gov.au/climate/ averages/tables/cw_002014.shtml].

90. Harrison L, McGuire L, Ward S, Fisher A, Pavey C, Fegan M, Lynch B: An Inventory of Sites of International and National Significance for Biodiversity Values in the Northern Territory. Darwin: Department of Natural Resources, Environment, The Arts and Sport; 2009.

91. Frair JL, Fieberg J, Hebblewhite M, Cagnacci F, DeCesare NJ, Pedrotti L: Resolving issues of imprecise and habitat-biased locations in ecological analyses using GPS telemetry data. Phil Trans R Soc B 2010, 365:2187-2200

92. Kenward RE, Clarke RT, Hodder KH, Walls SS: Density and linkage estimators of home range: nearest-neighbour clustering defines multinuclear cores. Ecology 2001, 82:1905-1920.

93. Kenward RE, Walls SS, South AB, Casey N: Ranges8: For the Analysis of Tracking and Location Data. Online Manual. Wareham: Anatrack Ltd; 2008.

doi:10.1186/2050-3385-1-7

Cite this article as: Price-Rees et al:: Habitat selection by bluetongue lizards (Tiliqua, Scincidae) in tropical Australia: a study using GPS telemetry. Animal Biotelemetry 2013 1:7

\section{Submit your next manuscript to BioMed Central and take full advantage of:}

- Convenient online submission

- Thorough peer review

- No space constraints or color figure charges

- Immediate publication on acceptance

- Inclusion in PubMed, CAS, Scopus and Google Scholar

- Research which is freely available for redistribution
C Biomed Central 